\title{
Atividade bactericida dos extratos hidroalcoólicos de hera-roxa e capim-limão e dos óleos essenciais de orégano, tomilho e melaleuca sobre xanthomonas albilineans
}

\section{Bactericidal activity hydroalcoholic extracts rubrastilis and lemon grass and essential oils oregano, thyme and melaleuca on Xanthomonas albilineans}

Artigo

Original

\author{
Elizabeth Teixeira de Almeida Ramos ${ }^{1}$ \\ Kelly Carla A. de Souza Borges ${ }^{2}$ \\ Victor Maximiliano Reis Tebaldi ${ }^{2}$
}

Original

Paper

\section{Palavras-chave}

Métodos

fitossanitários

alternativos

Atividade

antibacteriana

Xanthomonas albilineans

\section{Resumo}

As conseqüências trazidas pelo uso indiscriminado de agrotóxicos como a contaminação, do solo, do lençol freático e de animais; intoxicação dos trabalhadores; além de promover a resistência de patógenos e pragas aos princípios ativos utilizados nos pesticidas, confirmam a necessidade de criação de métodos de controle fitossanitários alternativos. Baseandose no mecanismo de defesa de plantas, caracterizado como atividade elicitora e sua ação antibacteriana, em especial, o eminente trabalho teve como objetivo avaliar o efeito bactericida dos extratos hidroalcoólicos das plantas: Hemigraphis colorata (hera-roxa) e Cymbopogon citratus (capim-limão) e dos óleos essenciais de Origanum vulgare (orégano), Thymus vulgaris (tomilho) e Melaleuca alternifolia (melaleuca) sobre o fitopatógeno Xanthomonas albilineans, causador da doença dos cultivares de cana-de-açúcar, a escaldadura das folhas. Verificou-se suscetibilidade da bactéria testada frente aos óleos essenciais de orégano e tomilho, com uma concentração mínima inibitória (CMI) de 7,81 $\mu \mathrm{L}$ / $\mathrm{mL}$ e insensibilidade aos extratos hidroalcóolicos de capim-limão e heraroxa e ao óleo essencial de melaleuca.

\section{Abstract}

The consequences brought about by the indiscriminate use of pesticides such as pollution, soil, groundwater and animals, intoxication workers, and promote resistence to pests and pathogens of active ingredients used in pesticides, confirm the need to create methods akternative phytosanitary control. Relying on the defense mechanism of plants, characterized activity aselitors and their antibacterial action, in particular, the eminent work was to evaluate the bactericidal effect of hydroalcoholic extracts os plants: Hemigraphis colorata (rubrastilis) e Cymbopogon citratus (grass-lime) and essential oils Origanum vulgare (oregano), Thymus vulgaris (thyme) e Melaleuca alternifolia (tea tree) on the plant pathogen Xanthomonas albilineans, wich causes the disease of cultivars of cane sugar scald the leaves. There has been tested against bacteria's susceptibility to essential oils of oregano and thyme, with a minimum inhibitory concentration (MIC) of 7,81 $\mu \mathrm{L} /$ $m L$ and insensitivity to the hidroalcoholic extracts os lemon-grass and rubrastilis and the essential oil of melaleuca

\section{Key words}

Alternative plant

protection methods

Antibacterial activity

Xanthomonas

albilineans

Recebido em 10/2011

Aprovado em 08/2012 


\section{Introdução}

O modelo de produção agrícola brasileiro, historicamente, baseia-se na utilização de agrotóxicos para compensar problemas do processo produtivo. Neste contexto, os agrotóxicos foram introduzidos na agricultura brasileira como uma tentativa de corrigir as necessidades do solo e prevenir/eliminar as pragas que prejudicariam a produtividade.

$\mathrm{O}$ uso indiscriminado de agrotóxicos tem, indiscutivelmente, acarretado vários problemas de ordem ambiental, como a contaminação, do solo, do lençol freático e de animais; eliminação de organismos benéficos, além de promover a resistência de patógenos e pragas aos princípios ativos utilizados nos pesticidas. Porém, vendo-se pelo prisma da simplicidade, previsibilidade e necessidade de pouco entendimento sobre a ecologia e fisiologia das espécies, o uso dos agrotóxicos revelam-se como a principal escolha de agricultores. (MORANDI; BETTIOL, 2009).

O impacto causado por pesticidas no meio ambiente vem alcançando índices alarmantes, resultando na necessidade de uma busca por produtos eficazes, mas isentos de agrotóxicos, sendo estes portadores de selos que comprovem essa eficácia. (BETTIOL; GHINI, 2003).

Corroboramos aqui a ideia central de Bird et al. (1990), que elucida o conceito de agricultura sustentável mostrando que tal enfoque altera as prioridades dos sistemas convencionais de agricultura em relação ao uso de fontes não renováveis e muda a visão sobre os níveis adequados do balanço entre a população de alimentos e os impactos no ambiente.

As alterações implicam na redução da dependência por produtos químicos e outros insumos energéticos e o maior uso de processos biológicos nos sistemas agrícolas (BETTIOL; GHINI, 2003).

Para tais alterações, são como no explorado por Pereira et. al (2008) e Santurio et. al (2007), em que foi comprovado o efeito fungicida e bactericida, respectivamente, do óleo essencial de tomilho.

Resultado semelhante é encontrado também em Horne (2001), onde o agente antimicrobiano caracterizado por causar dano à membrana e provocar lise da célula do patógeno
Streptococcus pneumoniae, é atribuído aos óleos essenciais de orégano, jacarandá e tomilho.

Já para o óleo essencial de melaleuca, Carson; Hammer; Riley (2006) esclarecem que dados contemporâneos mostram que o espectro amplo deste óleo essencial inclui atividades antibacteriana, antifúngica, antiviral e antiprotozoário.

Resultados obtidos por Subramoniam et al. (2001) comprovam que a H. colorata possui propriedades cicatrizantes e anti-inflamatórias, necessitando de mais pesquisas, em razão do pouco conhecimento sobre tal espécie.

A alelopatia também tem sido verificada em extratos brutos, conforme em Figueiredo et.al (2002), em que confirma-se a atividade antifúngica, antibacteriana, anti-helmíntica, inseticida, diurética e anticarcinogênica do capim-limão (Cymbopogon citratus).

A exploração da atividade biológica de metabólitos secundários presentes no extrato bruto ou óleo essencial de plantas medicinais pode se constituir, ao lado da indução de resistência, em uma forma potencial de controle alternativo de doenças de plantas cultivadas, como o confirmado por Zacaroni et al. (2009)

Tais estudos suplementam a relevância de pesquisas descrita por Silva (2005), em que a bactéria Xanthomonas albilineans, patógeno de uma das principais doenças dos cultivares de cana-de-açúcar, a escaldadura das folhas, é apontado como causador de perdas significativas na produção.

Portanto, é nesse contexto que o presente trabalho objetiva avaliar a ação bactericida dos extratos hidroalcoólicos das plantas: Hemigraphis colorata (hera-roxa) e Cymbopogon citratus (capim-limão) e dos óleos essenciais de Origanum vulgare (orégano), Thymus vulgaris (tomilho) e Melaleuca alternifolia (melaleuca) sobre o fitopatógeno: Xanthomonas albilineans.

\section{Material e métodos}

\subsection{Material botânico e obtenção dos extratos hidroalcoólicos}

Foram estudadas as plantas Hera-roxa (Hemigraphis colorata), coletada no Horto da Cidade Universitária UFRJ, e Capim-limão 
(Cymbopogon citratus), cuja coleta foi realizada em canteiro residencial na cidade de Pinheiral, RJ

Primeiramente, as partes aéreas foram pesadas obtendo-se 621,9 g (capim-limão) e 438,32 g (hera-roxa), referente ao peso fresco.

Em seguida foram secas em estufa a $42^{\circ} \mathrm{C}$ com circulação de ar, para eliminação da umidade e estabilização do conteúdo enzimático.

Para obtenção dos extratos foi utilizado como solvente álcool etílico absoluto/água a $70 \%$. Foram realizadas trocas do solvente duas vezes por semana, para melhor remoção e aproveitamento dos metabólitos secundários.

Posteriormente, dois litros de cada um dos extratos foram submetidos ao rota evaporador, disponível no Laboratório de Química da Universidade Estadual da Zona Oeste (UEZO), sob a temperatura de $85^{\circ} \mathrm{C}$ (Capim-limão) e $75^{\circ} \mathrm{C}$ (Hera-roxa), para evaporação do etanol.

Tais extratos concentrados foram submetidos ao banho-maria à temperatura de $50^{\circ} \mathrm{C}$ para evaporação da água e conseguinte obtenção dos extratos brutos (E.B), os quais foram diluídos em DMSO (Dimetilsufóxido).

\subsection{Obtenção dos óleos essenciais}

Foram avaliados quanto à atividade antibacteriana os óleos essenciais de Melaleuca alternifolia (melaleuca), Thymus vulgaris (tomilho) e Origanum vulgaris (orégano) adquiridos da empresa Ferquima Ind. e Com. Ltda.

\subsection{Micro-organismo teste e preparação do inóculo}

Os testes foram realizados frente à bactéria gram-negativa: Xanthomonas albilineans (ATCC 11724), fornecida pelo INCQS - Coleção de Micro-organismos de Referência do Instituto Oswaldo Cruz IOC/FIOCRUZ.

Os inóculos foram obtidos preparando-se suspensões padronizadas pela turvação equivalente ao tubo 0,5 da escala de McFarland em solução fisiológica de $\mathrm{NaCl}$ 0,85\% (p/v).

\subsection{Avaliação da concentração inibitória}

Para a determinação da concentração inibitória mínima (CIM), empregou-se o méto- do de difusão cavidade em ágar Brain Heart Infusion (BHI), conforme descrita por Deans; Ritchie (1987) adaptada por Mendonça (2004).

Placas de Petri estéreis de 140 x 15 mm foram preparadas com ágar BHI fundido.

Após a solidificação do meio de cultura, pérolas de vidro de 3-4 mm estéreis foram devidamente posicionadas com auxílio de uma pinça esterilizada.

Em seguida verteu-se sobre a placa com as pérolas de vidro, ágar BHI fundido contendo $2 \mathrm{~mL}$ do inóculo.

Para a obtenção das cavidades, após a solidificação do ágar, as pérolas de vidro foram retiradas utilizando a pinça.

\subsection{Determinação da concentração mí- nima inibitória (cmi)}

As diluições foram realizadas em dimetilsulfóxido (DMSO) para os extratos e etanol absoluto para os óleos essenciais, resultando nas seguintes concentrações utilizadas: 500; $250 ; 125 ; 62,5 ; 31,25 ; 15,62 ; 7,81 ; 3,90 \mu \mathrm{L} /$ $\mathrm{mL}$, respectivamente.

Foram aplicados $10 \mu \mathrm{L}$ de cada concentração dos extratos e dos óleos essenciais nas cavidades formadas no meio de cultura.

As placas foram incubadas em estufa a $37^{\circ} \mathrm{C}$ por 24 horas. Após esse período, foi verificada a presença de halos ao redor dos orifícios e medidos os diâmetros dos halos com auxílio de um paquímetro.

Os testes foram realizados em triplicata e os resultados expressos em mm pela média aritmética do diâmetro dos halos de inibição formado ao redor das cavidades nas 3 repetições.

O teste controle foi feito aplicando-se $10 \mu \mathrm{L}$ de DMSO na cavidade central das placas com extrato hidroalcoólico e $10 \mu \mathrm{L}$ de etanol nas cavidades das placas referente aos óleos essenciais.

\subsection{Análise estatística}

Para os dados estatísticos foram utilizados a análise de regressão linear e o teste $\mathrm{T}$, para a comparação de médias dos halos de inibição. Os testes foram considerados significantes quanto o valor de $\mathrm{P}$ foi menor que 0,05 . 


\section{Resultados e discussão}

Do peso fresco inicial obteve-se $279,1 \mathrm{~g}$ (capim-limão) e 49,09 g (hera-roxa) de peso seco, dos quais foram obtidos $12,7 \mathrm{~g}$ e 9,6 $\mathrm{g}$ de extrato bruto (E.B) de capim-limão e hera-roxa, respectivamente.

Os extratos hidroalcoólicos de capim-limão e hera-roxa não promoveram formação de halos de inibição sobre Xanthomonas albilineans, verificando-se resistência ou insensibilidade a estes extratos.

Corroborando os resultados de Alvarenga et. al (2007), em que o efeito de extratos aquoso e etanólico de capim-limão foram ineficazes sobre as bactérias Streptococcus aureus, $S$. choleraesuis, S. mitis e S. mutans à concentração de $10 \%$.

Porém, na mesma pesquisa (ALVARENGA, 2007), sob a concentração de $20 \%$, os extratos etanólicos levaram à formação de halos de inibição intermediária de Shigella flexneri.

Já nos estudos de Schuck et. al (2001), ao analisar a atividade antimicrobiana dos extratos aquosos e etanólicos de Cymbopogon citratus sobre os micro-organismos: Staphylococcus aureus, Escherichia coli e Candida albican, foi observada atividade antibacteriana referente ao extrato aquoso somente sobre $S$. aureus, enquanto o extrato etanólico não apresentou nenhum efeito sobre os microganismos testados.

A espécie Hemigraphis colorata (Heraroxa) pertence à família Acanthaceae, a qual necessita de pesquisas para elucidar seus potenciais. Como em Larcher; Boeger (2006), onde é citada a família Acanthaceae como uma das poucas famílias que apresentam certas estruturas nas folhas - cistólitos, relacionados à invasão de fungos e proteção à herbivoria.

Através dos ensaios microbiológicos verificou-se que o óleo essencial de melaleuca não apresentou atividade antibacteriana, refletindo assim, os estudos de Carson; Mee; Riley (2002) em que não foi observado efeito antibacteriano sobre Staphylococcus aureus usando-se o mesmo óleo essencial.

Em contrapartida, pesquisa realizada por Packer; Luz (2007) sobre a atividade antibacteriana do óleo essencial de melaleuca sobre Staphylococcus aureus, Escherichia coli, Pseudomonas aeruginosa e Candida albicans demonstrou ótimo desempenho bacteriostático, assim como o apresentado por Hada et. al (2003), que comprovaram suscetibilidade de $S$. aureus ao óleo essencial de melaleuca.

Já para os óleos essenciais de tomilho e orégano verificou-se considerável atividade antibacteriana frente à Xanthomonas albilineans (Figura 1), com halos de inibição que variaram entre 3,5 a $23 \mathrm{~mm}$ e 1,2 a $15,8 \mathrm{~mm}$, respectivamente (Tabela 1).

O resultado da análise de regressão linear demonstrou que os dados encontrados foram significativos em referência à sensibilidade da bactéria Xanthomonas albilineans ( $\mathrm{p}=0,0003$ ).

Apesar de as médias dos halos de inibição referentes ao óleo essencial de tomilho serem relativamente maiores às formadas pelo óleo essencial de orégano, de acordo com a comparação de médias feita pelo teste $T$, não houve diferenças significativas entre os tratamentos $(p=0,3862)$.

Tabela 1 - Concentração Mínima Inibitória (CMI) dos óleos essenciais de orégano e tomilho Diâmetro dos Halos de inibição (mm)

\begin{tabular}{ccc}
\cline { 2 - 3 } Concentrações $(\boldsymbol{\mu L} / \mathbf{m L})$ & Orégano & Tomilho \\
\cline { 2 - 3 } 500 & 13,4 & 21,0 \\
250 & 15,8 & 23,0 \\
125 & 13,0 & 15,5 \\
62,5 & 11,5 & 11,4 \\
31,5 & 6,0 & 8,3 \\
15,62 & 5,0 & 5,0 \\
7,81 & 1,2 & 3,5 \\
3,9 & 0,0 & 0,0 \\
& $*$ &
\end{tabular}




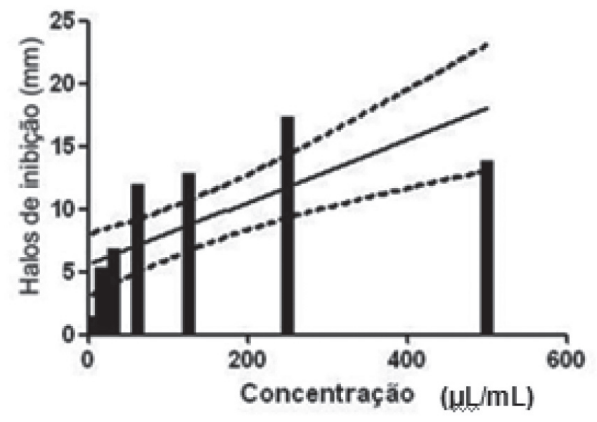

a)

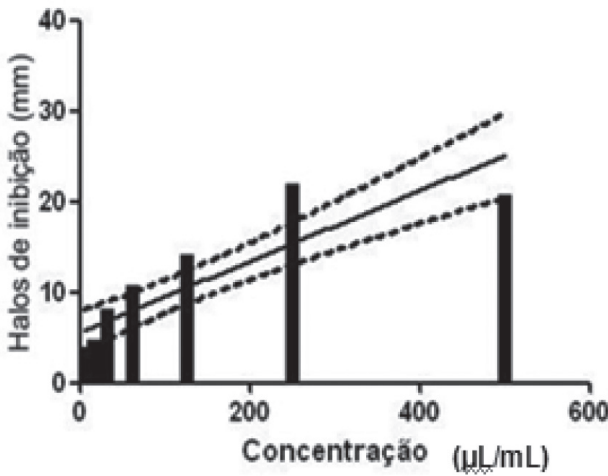

b)

Figura 1 - Efeito de diferentes concentrações na formação dos halos de inibição de orégano (a) e tomilho (b)

Santurio et. al (2007) ao testarem o efeito inibitório dos óleos essenciais de orégano e tomilho sobre sorovares de Salmonella, observaram dados semelhantes aos reportados nesta pesquisa, diferindo apenas pela formação de halos de inibição ligeiramente maiores referente ao óleo essencial de orégano quando comparados aos halos de inibição formados pelo óleo essencial de tomilho.

Souza et. al (2008) comprovaram também o efeito bactericida do óleo essencial de orégano frente à Candida albicans, C. krusei, C. tropicalis, Bacillus cereus, Escherichia coli, Staphylococcus aureus, Yersinia enterocolitica, Salmonella enterica, Serratia marcencens, ressaltando que o responsável por tal atividade é o carvacrol, um dos compostos majoritários encontrados através da análise cromatográfica.

Resultado semelhante foi encontrado por Pozzo (2011), ao avaliar o efeito antibacteriano dos óleos essenciais de orégano e tomilho sobre 33 isolados de Staphylococcus spp, enfatizando para a maior concentração de carvacrol e timol, explicando assim sua capacidade antibacteriana.

Segundo o perfil cromatográfico emitido pela empresa fornecedora dos óleos essenciais, foram encontrados $70 \%$ do composto carvacrol, 3,5\% do composto timol e 4,5\% do composto gama-terpineno como componentes majoritários do óleo essencial de orégano.

Esses resultados corroboram com os estudos de Silva et. al (2010) que encontraram grandes picos indicando o carvacrol como principal componente,com variação entre $61,7 \%$ a $93 \%$, seguindo com o timol com variação de $1,88 \%$ a $23,85 \%$ e o gama-terpineno $-6,90 \%$.

Em Jerkovic; Mastelic e Milos (2001) é elucidado que a composição do óleo essencial de orégano é influenciada pelo local de plantio, época da colheita,sendo que no período de florescimento observou-se a maior concentração dos componentes identificados. Já os dados cromatográficos do óleo essencial de tomilho revelaram como componente majoritário 40\% referente ao composto timol, como em Jakiemiu et. al (2010), onde foi encontrado $54 \%$ à $57 \%$ do composto timol, ao ser estudado a composição e o rendimento do óleo essencial de tomilho.

Os dados referentes à cromatografia do óleo essencial de melaleuca revelaram como componentes majoritários $40 \%$ do composto terpineno-4-ol, 22,3\% do composto gama-terpineno, $10,8 \%$ do composto alpha terpineno e $3 \%$ do composto cineol.

Assim como o encontrado nos estudos feitos por Silva et. al (2003), que ao realizar a análise dos constituintes químicos e da atividade antimicrobiana do óleo essencial de melaleuca, encontrou 46,38\% do composto terpineno-4-ol, $3,72 \%$ do composto cineol, $9,74 \%$ do composto gama-terpineno, $4,35 \%$ do composto alpha terpineno e $16,52 \%$ do composto p-cimeno.

\section{Conclusões}

De acordo com os dados abordados, conclui-se que os extratos hidroalcóolicos de capim -limão e hera-roxa e o óleo essencial de melaleuca não apresentaram atividade antibacteriana para o micro-organismo testado. Enquanto os óleos essenciais de orégano e tomilho apresentaram notável atividade frente à Xanthomonas albilineans. Ambos os óleos essenciais apresentaram resultados estatisticamente semelhantes contra o micro-organismo testado. 


\section{Agradecimentos}

Agradeço às técnicas de laboratório Renata Coutinho e Thais Boechat pelo auxílio prestado, à UEZO por ter cedido o espaço laboratorial e ao Instituto Oswaldo Cruz IOC/ FIOCRUZ

\section{Referências bibliográficas}

1. ALVARENGA, A.L. et. al. Atividade antimicrobiana de extratos vegetais sobre bactérias patogênicas humanas. Revista Brasileira de Plantas Medicinais, Botucatu, v.9, n.4, p. 86-91, 2007.

2. BETTIOL, W.; GHINI. R. Proteção de plantas em sistemas agrícolas alternativos. In: CAMPANHOLA. C. E BETTIOL, W Métodos alternativos de controle fitossanitário. 1. ed. São Paulo: Embrapa Meio Ambiente, 2003. p. 79-95

3. BIRD, G. W. et al. Design of pest management systems for sustainable agriculture. In: FRANCIS, C. A. et al. Sustainable Agriculture in Temperate Zones.2. ed. New York: Jonh Wiley, 1990. p. 55-110.

4. CARSON, C. F.; HAMMER, K. A.; RILEY, T. V. Melaleuca alternifolia (Tea Tree) Oil: a Review of Antimicrobial and Other Medicinal Properties. Clinical Microbiology Reviews, American Society for Microbiology, v. 19, n.1, p 50-62, 2006

5. CARSON, F. C.; MEE, B. J.; RILEY, T. V. Mechanism of Action of Melaleuca alternifolia (Tea Tree) Oil on Staphylococcus aureus Determined by Time-Kill, Lysis, Leakage, and Salt Tolerance Assays and Electron Microscopy, Antimicrobial Agents and Chemotherapy, American Society for Microbiology, v. 46, n.6, p. 1914-1920, 2002.

6. DEANS, S. G.; RITCHIE, G. Antibacterial properties of plant essential oils. International Journal of Food Microbiology, Amsterdan, n. 2, p. 165 $180,1987$.
7. FIGUEIREDO, R. O., et al. Effect of growth regulators in citral content in lemongrass in different seasons. Acta Horticulturae, Amsterdam, v. 569, n. 22, p. 47-49. 2002.

8. HADA T., et. al. Leakage of $\mathrm{K}+$ ions from Staphylococcus aureus in response to tea tree oil. J, Microbiol Methods, v. 53, p. 309-312, 2003

9. HORNE, D. S. M. et. al. Antimicrobial effects of essential oils on Streptococcus pneumoniae. J. Essent. Oil, v. 13, p. 387392, 2001.

10. JAKIEMIU et. al Estudo da composição e do rendimento do óleo essencial de tomilho (Thymus vulgaris L.), Ciências Agrárias, Londrina, v. 31, n. 3, p. 683-688, 2010.

11. Jerkovic, I.; Mastelic, J.; Milos, M. The impact of both the season of collection and drying on the volatile constituents of Origanum vulgare L. ssp. hirtum grown wild in Croatia. International Journal of Food Science and Technology, v. 36, n. 6, p. 649-654, 2001.

12. LARCHER, L.; BOEGER, M. R. T. Anatomia foliar de Odontonema strictum (Nees) O. Kuntze (Acanthaceae), Biotemas, v.19, n. 4, p. 23-31, 2006

13. MENDONÇA, A. T. Efeito dos óleos essenciais de condimentos sobre o crescimento de Staphylococcus aureus em ricota cremosa. 2004. Tese (Doutorado em Ciências Biológicas). Universidade Federal de Lavras, Minas Gerais.

14. MORANDI, M. A. B.; BETTIOL, W. Biocontrole de Doenças de Plantas Usos e Perspectivas. In: MORANDI, M. A. B.; BETTIOL, W. Controle Biológico de Plantas no Brasil. 1. ed. São Paulo: Embrapa Meio Ambiente, 2009. p. 300- 334

15. PACKER, F.; LUZ, M. M. S. Método para avaliação e pesquisa da atividade antimicrobiana de produtos de origem natural, Revista Brasileira de Farmacognosia, v. 17, n.1, p. 102-107, 2007. 
16. PEREIRA, R. B. et. al. Extrato de casca de café, óleo essencial de tomilho e acibenzolar-s-metil no manejo da cercosporiose-do-cafeeiro. Pesquisa Agropecuária Brasileira, Brasília, v.43, n.10, p.1287-1296, 2008.

17. POZZO, M. D. et. al. Atividade antimicrobiana de óleos essenciais de condimentos frente a Staphylococcus spp isolados de mastite caprina. Ciência Rural, Santa Maria, v. 41, n. 4, p. 667-672, .2011

18. SANTURIO, J. M. et. al. Atividade antimicrobiana dos óleos essenciais de orégano, tomilho e canela frente à sorovares de Salmonella enterica de origem avícola. Ciência Rural, Santa Maria, v.37, n.3, p. 803-808, 2007

19. SCHUCK, V. J. A. Avaliação da atividade antimicrobiana de Cymbopogon citratus Revista Brasileira de Ciências Farmacêuticas, Brazilian Journal of Pharmaceutical Sciences, vol. 37, n. 1, 2001.

20. SILVA, J. P. L. et. al Óleo essencial de orégano: interferência da composição química na atividade frente a Salmonella Enteritidis, Ciência e Tecnologia de Alimentos, Campinas, v.30, n. 1, p. 136-141, 2010.

21. SILVA, M. S. Caracterização sorológica, molecular e patogênica de isolados de Xanthomonas albilineans (Ashby) Dowson agente causal da escaldadura das folhas da cana-de-açúcar. 2005. Dissertação (Mestado em Agronomia), Universidade de
São Paulo, Escola Superior de Agricultura Luiz de Queiroz, São Paulo, 2005

22. SILVA, S., R., S. et. al. Análise dos contituintes químicos e da atividade antimicrobiana do óleo essencial de Melaleuca alternifolia Cheel, Revista Brasileira de Plantas Medicinais, Botucatu, v. 6, n. 1, p.63-70, 2003.

23. SOUZA, E. L. et.al. Interference of heating on the antimicrobial activity and chemical composition of Origanum vulgare L. (Lamiaceae) essential oil. Ciência e Tecnologia de Alimentos, Campinas, v. 28, p. 418-422, 2008

24. SUBRAMONIAM, D. et al. Effect of Hemigraphis colorata (blume) h. G. Hallier leaf on wound healing and inflammation in mice. Indian Journal of Pharmacology, v.33, p.283-285, 2001.

25. ZACARONI, M. et al. Potencial fungitóxico do óleo essencial de Piper hispidinervum (pimenta longa) sobre os fungos fitopatogênicos Bipolaris sorokiniana, Fusarium oxysporum e Colletotrichum gloeosporioides. Acta amazônica, v. 39, n. 1, p. 193-198, 2009.

\section{Endereço para Correspondência:}

Elizabeth Teixeira de Almeida Ramos

elizabethramos_vr@hotmail.com

Rua 4, n 198, Planalto do Sol

Pinheiral - RJ

CEP: 27197-000 